\title{
Miradas cruzadas en la repatriación de saberes. El caso de las grabaciones rituales náayeri registradas por K. Th. Preuss
}

Regards croisés dans la restitution des savoirs. Le cas des enregistrements rituels náayeri effectués par $K$. Th. Preuss

Crossed perspectives in the repatriation of knowledge. The Náayeri ritual recordings from $\mathrm{K}$. Th. Preuss

\section{Margarita Valdovinos Alba}

\section{OpenEdition}

\section{Journals}

Edición electrónica

URL: https://journals.openedition.org/jsa/19143

DOI: 10.4000/jsa.19143

ISSN: 1957-7842

Editor

Société des américanistes

Edición impresa

Fecha de publicación: 15 diciembre 2020

Paginación: 177-200

ISSN: 0037-9174

Referencia electrónica

Margarita Valdovinos Alba, «Miradas cruzadas en la repatriación de saberes. El caso de las grabaciones rituales náayeri registradas por K. Th. Preuss», Journal de la Société des américanistes [En línea], 106-2 | 2020, Publicado el 30 diciembre 2020, consultado el 16 septiembre 2022. URL: http:// journals.openedition.org/jsa/19143; DOI: https://doi.org/10.4000/jsa.19143 


\title{
Miradas cruzadas en la repatriación de saberes. El caso de las grabaciones rituales náayeri registradas por $\mathrm{K}$. Th. Preuss
}

\author{
Margarita VAldovinos Alba*
}

En 1906, el etnólogo alemán Konrad Theodor Preuss grabó con un fonógrafo más de 43 cilindros de cera con cantos ceremoniales náayeri. A finales del siglo pasado, esta colección de grabaciones se hizo accesible solo para un público especializado en el Archivo Fonográfico de Berlín. Una larga investigación permitió acceder a los cilindros de cera, presentar su contenido ante expertos rituales náayeri contemporáneos, preparar su publicación y distribuir discos compactos con una selección de estos cantos antiguos entre los miembros de la comunidad de donde las grabaciones eran originarias. En este artículo analizaré el proceso de retribución de esta colección antigua de cantos en la que los expertos rituales náayeri fueron participantes activos. Mi estudio tomará también en cuenta el impacto que ha tenido este proceso de repatriación en la documentación de versiones contemporáneas de este mismo tipo de cantos ceremoniales náayeri y su consiguiente publicación. [Palabras clave: náayeri (cora), canto ritual, ritual, grabación histórica, expedición etnográfica, Preuss (Konrad Th.).]

Regards croisés dans la restitution des savoirs. Le cas des enregistrements rituels náayeri effectués par K. Th. Preuss. En 1906, l'ethnologue allemand Konrad Theodor Preuss a enregistré des chants cérémoniels náayeri avec un phonographe sur plus de 43 cylindres de cire. Jusqu'à la fin du siècle dernier, seuls des spécialistes avaient accès à cette collection d'enregistrements conservée aux Archives phonographiques de Berlin. Une longue recherche a permis de rendre accessible ces cylindres de cire et de présenter leur contenu à des experts rituels náayeri actuels, en préparant leur publication et en distribuant des CD contenant une sélection de ces chants anciens aux membres de la communauté où ils avaient été originellement enregistrés. Dans cet article, j'analyse le processus de restitution de cette ancienne collection de chants, processus auquel les experts rituels náayeri ont activement participé. Mon étude s'intéresse aussi à l'impact de cette restitution sur la documentation de versions contemporaines de ce même type de chants cérémoniels náayeri puis sur leur publication. [Mots-clés : náayeri (Cora), chant rituel, rituel, enregistrement historique, expédition ethnographique, Preuss (Konrad Th.).]

* Instituto de Investigaciones Filológicas, Universidad Nacional Autónoma de México, Coyoacán, Ciudad de México [margarita_valdovinos@hotmail.com]. 
Crossed perspectives in the repatriation of knowledge. The Náayeri ritual recordings from K. Th. Preuss. In 1906 the German ethnologist Konrad Theodor Preuss recorded Náayeri ceremonial chants in more than 43 wax cylinders. At the end of last century, this collection was accessible only for a specialized public in the Berlin Phonographic Archive. A large research project was conducted in order to allow access to these wax cylinders by presenting their content to Náayeri ritual experts, preparing its edition and distributing CD's with a selection of historic chants among the members of the Náayeri community from where the recordings were originally made. In this paper, I will analyze the retribution process of this ancient collection of chants in which the Náayeri ritual specialists have played an active role. My study will also consider the impact that this repatriation process had on the documentation of contemporary versions of the same kind of Náayeri ceremonial chants and its subsequent edition. [Key words: Náayeri (Cora), ritual song, ritual, historic recording, ethnographic expedition, Preuss (Konrad Th.).]

Hace dos décadas comencé a estudiar los materiales que el etnólogo Konrad Theodor Preuss (1869-1938) registró sobre los náayeri de Nayarit ${ }^{1}$ en 1906. Preuss analizó y tradujo una serie de textos en lengua cora relacionados con las prácticas ceremoniales de este pueblo y con sus creencias religiosas. Su trabajo fue publicado originalmente en 1912 en una edición bilingüe cora-alemán que no llegó a ser muy conocida en México sino hasta hace relativamente poco (ver Neurath y Jáuregui 1998, p. 15-60)².

Mi exploración sobre los textos náayeri de Preuss me llevó a incursionar en dos direcciones. Por un lado, me concentré en registrar y en entender el mismo tipo de prácticas rituales náayeri que tenían lugar en el momento en el que yo realizaba mi trabajo de campo. Esto me llevó a realizar nuevos registros de los cantos rituales náayeri. Por otro lado, me enfoqué en entender el modo de proceder del etnólogo adentrándome en sus archivos ${ }^{3}$. Allí localicé distintos

1. Los náayeri, mejor conocidos como Coras en la literatura etnográfica de México (Jáuregui 2004), conforman una de las 68 agrupaciones que hablan una lengua amerindia: el cora (INALI 2008). Se trata de cerca de 25000 personas que habitan en la sección de la Sierra Madre Occidental que atraviesa el estado de Nayarit. Organizadas en comunidades agrarias, sus distintas poblaciones hablan distintas variantes dialectales de la lengua y se organizan alrededor de gobiernos tradicionales con prácticas político-religiosas cercanas e interconectadas. Se caracterizan por la gran cantidad de rituales que celebran al año, llegando a comprender hasta 200 días (Valdovinos 2002).

2. Recientemente vio la luz la edición en español del libro de Preuss La expedición al Nayarit (2020). Esta nueva edición presenta el material cora de Preuss y su análisis acompañado de un nuevo estudio crítico sobre sus métodos y sobre la naturaleza de los textos que presenta.

3. Me centré en tres fondos particulares: los fondos especiales Preuss resguardados en la Biblioteca del Instituto Ibero-Americano de Berlín (Ibero-Amerikanisches Institut), los archivos de Preuss ubicados en el Archivo Histórico del Museo Etnológico de Berlín (Ethnologisches Museum) y la colección Preuss del Archivo Fonográfico de Berlín (Berliner Phonogramm-Archiv), ubicado también en el Museo. 
materiales aún no publicados sobre sus investigaciones, entre los que destacaba una serie de cilindros de cera que contenían grabaciones de cantos rituales náayeri (Figura 1).

Luego de analizar los materiales contemporáneos y los históricos, procedí a desarrollar distintos proyectos editoriales para publicar los resultados y dar a conocer la tradición poética náayeri ligada a sus prácticas rituales a través del tiempo. En particular, me interesaba devolver a los náayeri una nueva perspectiva de los registros históricos de sus tradiciones. En este trabajo analizaré el proceso de restitución de las grabaciones realizadas por Preuss a la

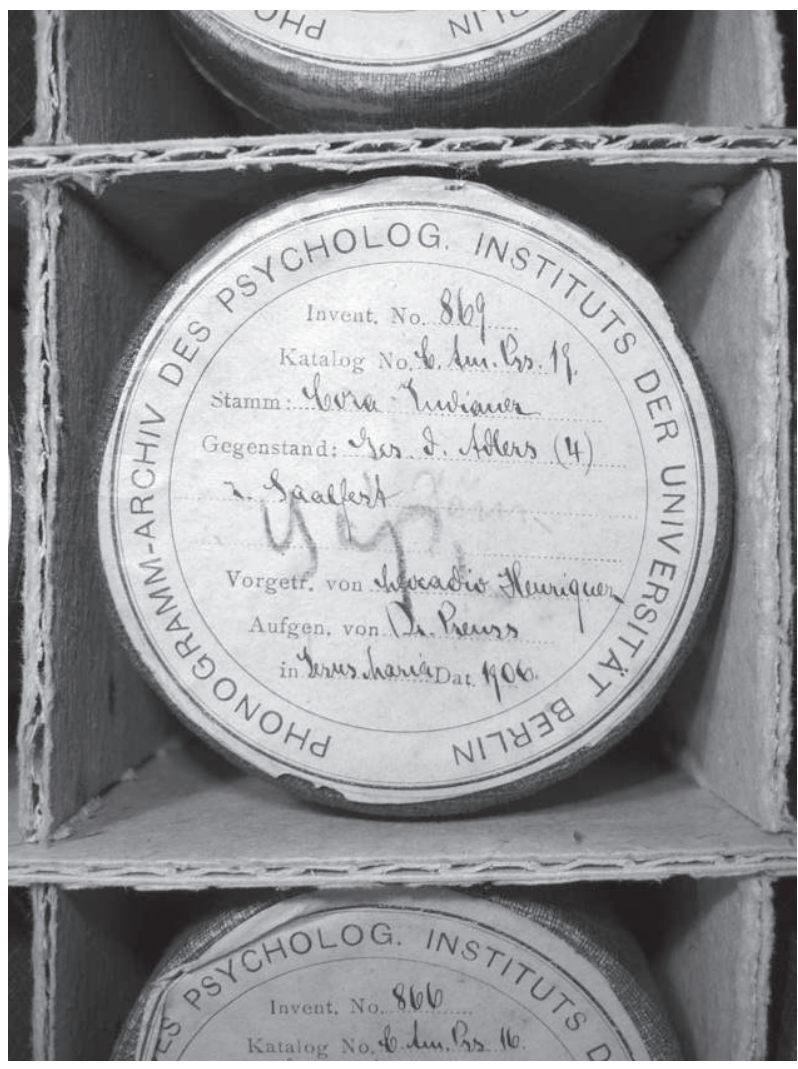

Fig. 1 - Tapa de un cilindro de la colección Preuss (foto M. Valdovinos Alba, 2005) comunidad cora de Jesús María en donde fueron originalmente realizadas.

Organizaré el texto en tres partes. En primer lugar, abordaré el contexto en el que se dio el trabajo de Preuss y el registro de su material. En segundo lugar, vincularé mi investigación sobre el material reunido por Preuss con el registro de materiales que llevé a cabo sobre las expresiones contemporáneas del mismo tipo de cantos ceremoniales; sobra decir que ambos corpora-el recopilado por Preuss y el que yo recopilé cien años más tarde- han sido indispensables para entender el contenido y la forma de los cantos rituales náayeri. En tercer lugar, analizaré el proceso de repatriación que se desarrolló alrededor del material registrado por Preuss en forma de grabaciones, deteniéndome en los efectos que ha tenido este modo de proceder sobre la difusión del saber especializado de los cantos ceremoniales náayeri. 


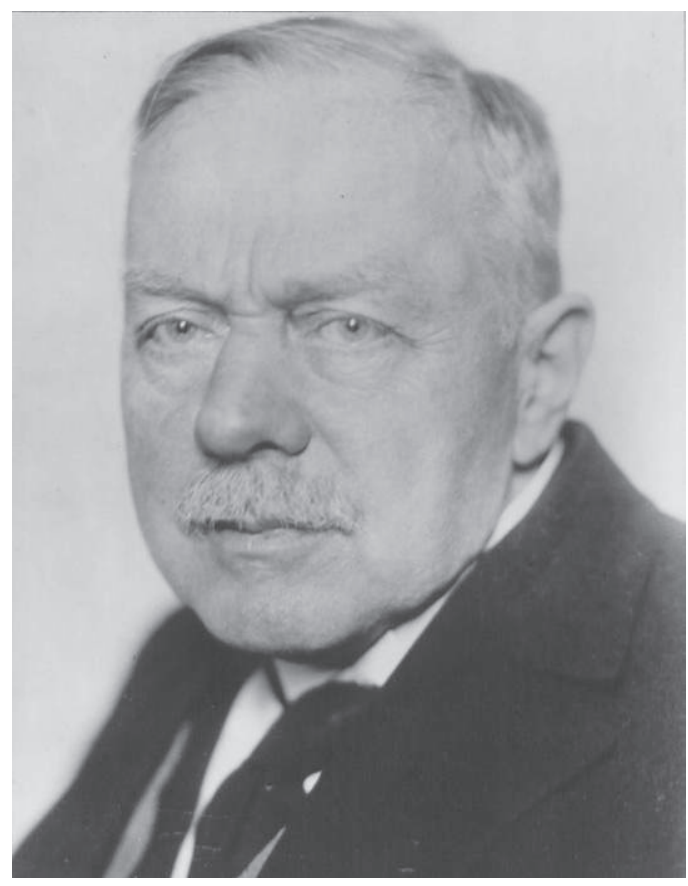

Fig. 2 - Konrad Theodor Preuss (1869-1938; foto del acervo de Preuss del Fondo Reservado del Instituto Ibero-Americano de Berlín)

\section{Konrad Theodor Preuss y los cantos de mitote}

El etnólogo prusiano Konrad Theodor Preuss (Figura 2) trabajaba como curador en el Museo Etnológico de Berlín cuando realizó su expedición al Occidente de México (1905-1907). Las culturas de esta región habían despertado el interés del público en esa época luego de que Carl Lumholtz (1851-1922) publicara una serie de trabajos sobre la cultura material de los huicholes, uno de los pueblos indígenas que habitan esta región (Lumholtz 1900, 1902). En el panorama intelectual alemán, estos nuevos materiales etnográficos recolectados para el Museo Americano de Historia Natural (American Museum of Natural History) emergían, ofreciendo nueva luz en un momento clave: en Alemania, bajo la batuta de Eduard Seler (1849-1922), comenzaban a estudiarse en profundidad distintos códices y pinturas murales del México prehispánico, en particular los que habían sido reportados por Alexander von Humboldt luego de su viaje a México (ver Humboldt 1810).

En un principio, el viaje de Preuss tenía la intención de reunir una colección de objetos arqueológicos de las culturas de la Sierra Madre Occidental para el Museo Etnológico de Berlín. Sin embargo, la exploración arqueológica de Preuss no pudo concretarse debido a la existencia de una nueva prohibición para extraer del país objetos arqueológicos (ver Valdovinos 2013c, p. 165-196). El etnólogo aprovechó estas circunstancias para reorientar su expedición y concentrarse en recopilar, además de material etnográfico, registros lingüísticos y literarios sobre las prácticas religiosas de los pueblos que visitó: coras, huicholes y mexicaneros (Figura 3).

Se sabía ya en aquella época que las lenguas habladas por estos tres pueblos mantenían una estrecha relación con la lengua de los antiguos mexicanos (ver Buschmann 1859), lo que impulsó más a Preuss a ver en sus prácticas literarias los vestigios de una tradición más antigua y, por ende, a concentrar gran parte de sus esfuerzos en recopilar la mayor variedad de este tipo de expresiones. 
El caso de las grabaciones rituales náayeri registradas por K. Th. Preuss

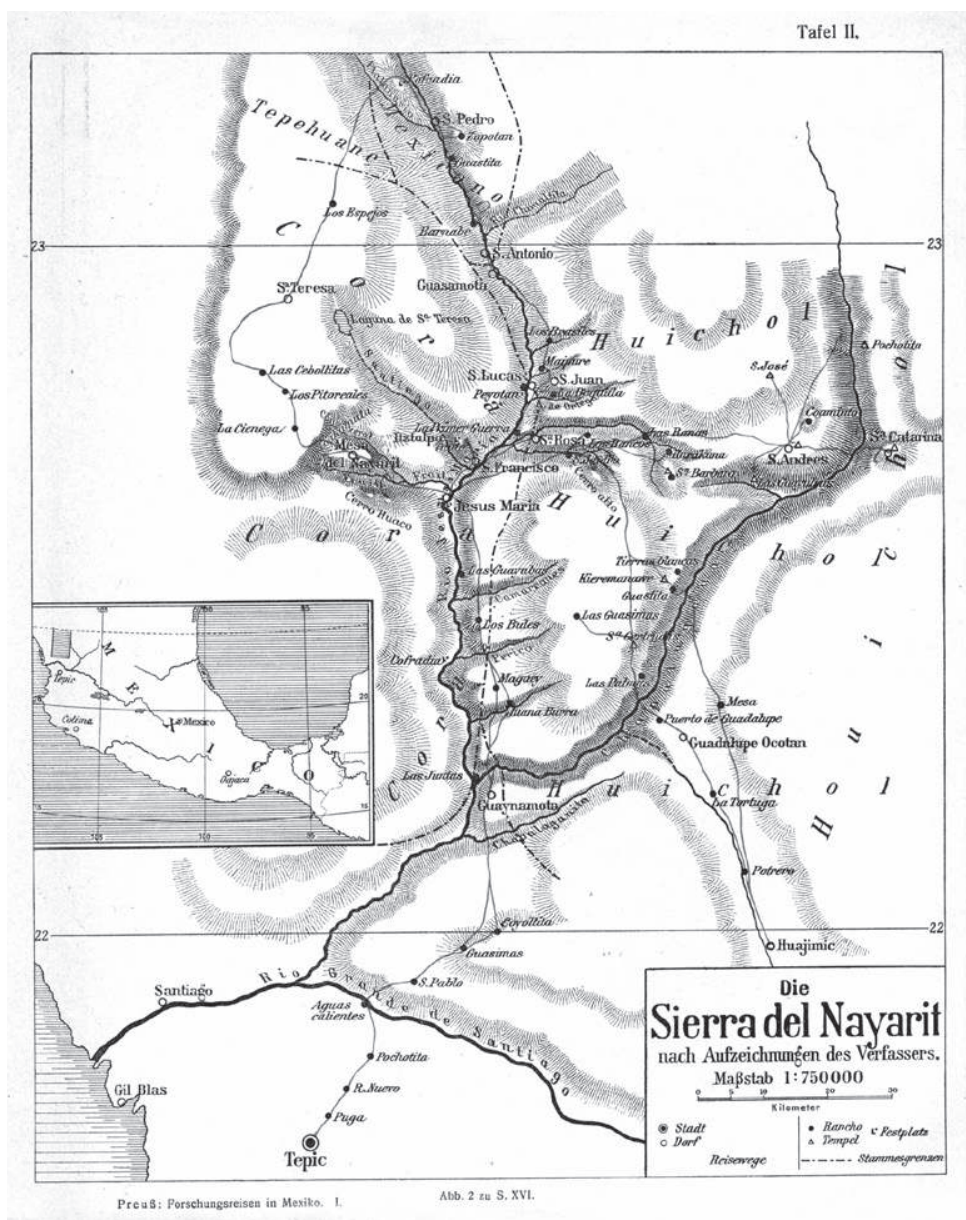

Fig. 3 - El recorrido de Preuss en la Sierra Madre Occidental

(1906-1908; imagen tomada del libro Die Nayarit-Expedición [Preuss 1912])

Así, desde el inicio de su expedición, el trabajo de Preuss fue orientándose en identificar, documentar, traducir y analizar tanta expresión literaria ligada a las prácticas rituales autóctonas como le fuera posible.

Una vez en la Sierra Madre Occidental, Preuss se instaló en la comunidad cora de Jesús María y, apenas unos días después de su llegada, tuvo la suerte de presenciar una ceremonia particular conocida entre quienes hablan español como "mitote"4. Este tipo de rituales dedicados al maíz se celebran aún en nuestros

4. En lengua cora, estas ceremonias se denominan utilizando el término mehtyínyeita 'aka seguido del sustantivo que hace referencia a un elemento distintivo ligado al ciclo de vida del maíz que corresponde temporalmente con cada una de las tres celebraciones del año. 


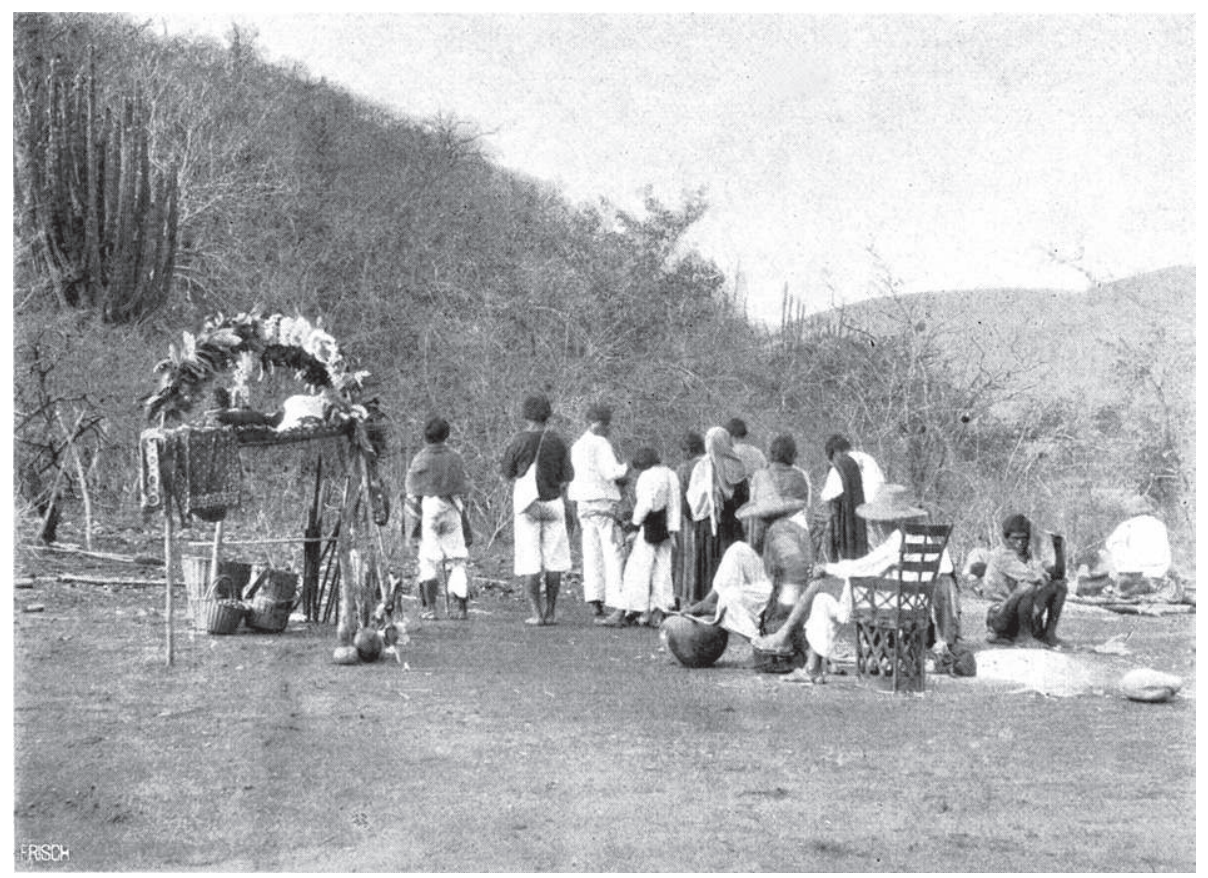

Fig. 4 - Mitote de Jesús María (foto K. Th. Preuss, 1906)

días tres veces al año y se caracterizan por la presencia de una serie de danzas -como lo indica el término náhuatl mitotia (danzar)- organizadas alrededor de la enunciación de un canto que se prolonga toda la noche. La ceremonia suele durar de tres a cinco días durante los cuales se realizan diferentes sesiones de plegaria y libaciones. La danza y el canto dan paso a la fase central del ritual, en la que se evoca la llegada de distintas divinidades al espacio ceremonial y se celebra la entrega del maíz a los humanos para su consumo. La interacción entre los cantos y las danzas narra la acción ritual evocando distintos pasajes de la mitología náayeri (Valdovinos 2008).

A Preuss le pareció haber encontrado en los mitotes el contexto perfecto para estudiar los textos religiosos náayeri (Preuss 1912, 2020), así que se dedicó a buscar la manera de registrar y de traducir sus cantos. Preuss se concentró entonces en estudiar estas manifestaciones ceremoniales en detalle (Figura 4), pues además de permitirle cumplir con sus intereses filológicos, le ofrecían un despliegue de los objetos rituales que se dedicó a coleccionar para enviar al Museo Etnológico de Berlín y cumplir con parte de los compromisos que le

Puesto que aquí hacemos referencia al conjunto de las manifestaciones de este tipo de ceremonias sin distinguir sus manifestaciones específicas, utilizaremos el término 'mitote' para referirnos a todas ellas. 
permitían financiar su expedición (Valdovinos 2013c, p. 165-196). Así, mientras coleccionaba objetos e iba mandándolos a Alemania, fue estableciendo paralelamente una metodología de trabajo etnolingüístico.

Entre los coras, Preuss dedicó gran parte de su tiempo primero a buscar colaboradores que conocieran la tradición de los cantos de mitote, y luego a trabajar con ellos y con un intérprete para realizar registros escritos de estas manifestaciones. A partir de este material, Preuss analizó las ideas y las prácticas religiosas de los pueblos indígenas del Occidente de México y su relación con las tradiciones de los antiguos mexicanos (Preuss 1912, p. XXIII-CV).

Básicamente, su proceder consistía en retomar las herramientas metodológicas utilizadas en ese entonces por la filología clásica en Alemania y adaptarlas a la realidad etnográfica que tenía enfrente: las artes verbales amerindias (Valdovinos 2012, p. 67-86). Tal como se procede en las escuelas de documentación lingüística en la actualidad, Preuss tomaba como punto de partida la recolección de textos. A partir de ellos comenzaba a analizar la lengua y a establecer una ortografía para su transcripción (Valdovinos 2020a, p. 503526). El análisis de los textos le permitía después hacer observaciones sobre la estructura de la lengua, generar un diccionario (Preuss 1912, p. 299-366) y plantear una gramática (Preuss 1932).

En su proceder, además de elaborar registros escritos de textos en lengua vernácula, realizaba una traducción al español, lengua que él mismo usaba para comunicarse con los indígenas. Procedía a revisar sus traducciones al español con ayuda de su intérprete y de los expertos que le dictaban sus cantos y narraciones. Siempre dejó para más tarde la traducción de sus materiales al alemán; aunque no hay evidencias concretas, sus archivos hacen suponer que tradujo a su lengua nativa los textos coras una vez de vuelta en Berlín.

En el campo, Preuss organizaba sesiones de dictado en las que pedía a los especialistas (Figura 5) que le dictaran a modo de discurso hablado sus cantos (Preuss 1912, p. XV-XXII y CVI-CVIII). El etnólogo tomaba nota registrando los textos, luego revisaba su transcripción y finalmente elaboraba una traducción, palabra por palabra, con ayuda de su intérprete que hablaba español. Más tarde revisaba detenidamente el material y, en caso de que lo considerara necesario, en una sesión subsiguiente evocaba las dudas que había encontrado en sesiones anteriores para que fueran aclaradas. En algunos casos hacía pequeños ejercicios gramaticales para entender aspectos de la traducción y de la gramática (Valdovinos 2020c, p. CXXXI-CCXVIII) ${ }^{5}$.

5. Además de la traducción al alemán, Preuss dejó para más tarde una revisión exhaustiva de sus textos a nivel fonético, morfológico y sintáctico, de modo que sus transcripciones publicadas poseen una sistematicidad y regularidad asombrosas (Valdovinos 2020b, p. CI-CXIII). 


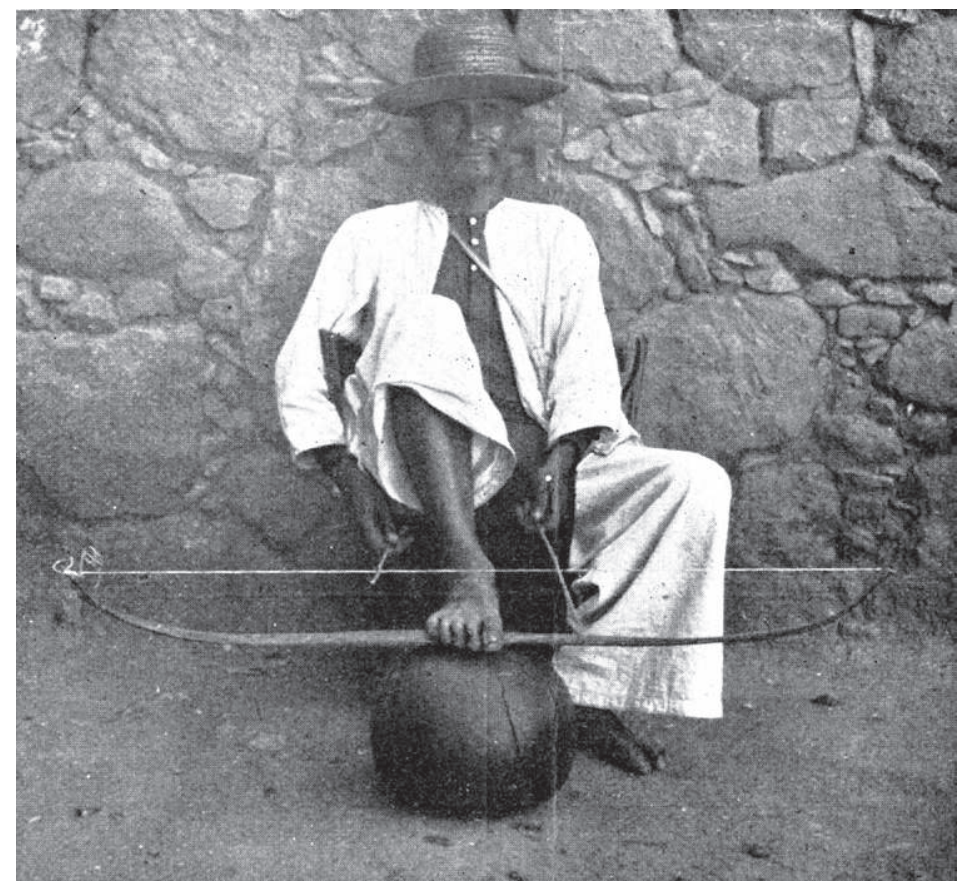

Fig. 5 - Especialista ritual (foto K. Ph. Preuss, 1906)

El material obtenido de esta forma se convertiría en la base de su libro Die Nayarit-Expedition (Preuss 1912), dedicado a las artes verbales náayeri ${ }^{6}$. Gracias a este libro se sabe que con este método Preuss registró al menos 149 textos coras. Además de estos textos, Preuss utilizó un fonógrafo para hacer registros de voz en cilindros de cera ${ }^{7}$. Realizó al menos 43 entre los coras y cerca de 55 entre los huicholes. Su idea era contar con ejemplos sonoros de los materiales que había reunido a través de dictados (ibid., p. 377-381).

A su vuelta a Alemania, Preuss intentó utilizar las grabaciones de los cilindros para estudiar su contenido, pero cuestiones técnicas se lo impidieron; muy pronto se percató de que este material no le permitía avanzar mucho en

6. Preuss realizó una copiosa documentación de textos ceremoniales también entre los huicholes y los mexicaneros. Sin embargo, los documentos recopilados entre los huicholes se perdieron durante la Segunda Guerra Mundial (Valdovinos 2012, p. 67-86) y los de los mexicaneros solo se conocen gracias a sus notas manuscritas, que luego fueron retomadas por Elsa Ziehm para un estudio detallado (Ziehm 1968, 1971 y 1976).

7. El Archivo Fonográfico de Berlín alberga otra importante colección americana de cilindros de cera que ha sido objeto de profundos análisis y de diversos procesos de restitución (Malvestitti 2012; Canio Llanquinao y Pozo Menares 2013). Me refiero aquí a la colección reunida por Robert Lehmann-Nitsche en Argentina (Lehmann-Nitsche 2009). 
su estudio (Valdovinos 2017, p. 223-239). En ese entonces, se utilizaban los cilindros originales para ser fundidos y elaborar moldes metálicos en negativo (galvanos), de los cuales se podían reproducir diversas copias que podían escucharse sin preocuparse por maltratar el original. Sin embargo, el procedimiento era manual y muchas veces podía no funcionar como era esperado. Al parecer este fue el caso de las grabaciones de Preuss, o al menos es lo que le pareció a Preuss luego de intentar usar las copias de sus grabaciones para analizar su contenido (Valdovinos y Ziehgler 2013, p. 73-75; Valdovinos 2013b, p. 89-93). De hecho, solo se conoce la transcripción que hizo de cinco cilindros que se encuentran en el apéndice de su libro La expedición al Nayarit para el estudio musical que realiza Eric von Hornbostel (ver Preuss 1912, p. 367-381). Allí Preuss confiesa la dificultad que enfrentó para acceder a los textos grabados y para proceder a su transcripción y traducción.

En 2005 tuve conocimiento de la existencia de las grabaciones de Preuss y pude acudir a escucharlas al Archivo Fonográfico (Phonogramm-Archiv) de Berlín. Paralelamente a mi proyecto editorial, que tenía como meta la edición en español y cora del libro de Preuss sobre los textos náayeri, me dediqué a estudiar sus grabaciones. El Archivo Fonográfico de Berlín había iniciado un proceso de digitalización y catalogación de sus fondos luego de la unificación de Alemania, cuando sus colecciones volvieron a reunirse (Wiedmann 2006, p. 56-58; Ziegler 2006). Así, gracias a los avances tecnológicos, pude escuchar las grabaciones coras con mucha mejor calidad que la que era posible alcanzar en los tiempos de Preuss. Me fue entonces posible realizar una primera transcripción del material y, con mis conocimientos sobre los cantos contemporáneos de mitote, identificar el contenido de todas las grabaciones de Preuss (Valdovinos 2013a, p. 77-82; 2013b, p. 89-93).

Después de casi 5 años de negociaciones institucionales, se me autorizó a obtener una copia de las grabaciones de Preuss para llevarlas al campo y poder escucharlas y analizarlas con los expertos rituales ${ }^{8}$. Con los resultados de esta investigación, y gracias al apoyo del Instituto Ibero-Americano de Berlín, se preparó la publicación de un CD con una selección de las grabaciones coras y huicholas de Preuss que se editó en la prestigiosa colección "Historische Klangdokumente" del Archivo Fonográfico de Berlín (Figura 6, página siguiente). El Instituto Nacional de Lenguas Indígenas contribuyó económicamente para que una parte de los CD pudieran ser distribuidos gratuitamente en las comunidades coras y huicholas en donde Preuss había grabado los cantos ceremoniales en 1906.

8. La dificultad para obtener el permiso residía en gran parte en el hecho de que la Unesco le había conferido a la colección de cilindros del Archivo Fonográfico de Berlín el título de Patrimonio de la Humanidad, y la administración del Museo Etnográfico era muy prudente con dejar salir el material. 


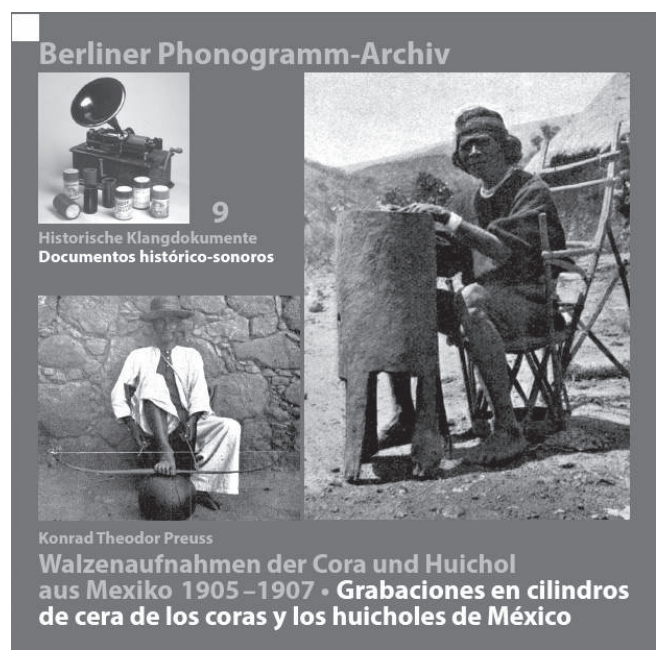

Fig. 6 - Portada de CD con la selección de los cantos recopilados por Preuss (2013)

\section{Un estudio contemporáneo sobre los cantos de mitote}

Mi primer intento por acercarme a los cantos de Preuss fue para realizar una traducción al español de los textos que él había publicado acompañados de su traducción al alemán en 1912. En un inicio, para una nueva edición de su libro nos pareció importante no recurrir a una doble traducción al pasar al español el texto con el que Preuss había traducido los cantos coras al alemán. Así que se adoptó la empresa de retomar la versión original y trabajarla con un grupo de profesores bilingües para obtener su traducción directamente al español.

A pesar de que los maestros bilingües contaban con muchas habilidades relacionadas con la lecto-escritura de su lengua, no lograron adentrarse en el contenido del material de Preuss y este primer intento de traducción fue todo un fracaso. Luego de tres meses sin poder avanzar a pesar de los esfuerzos, me dirigí a las autoridades tradicionales en busca de consejo. El entonces Gobernador segundo, Florentino Zeferino Celestino $(\dagger)$, me recomendó hablar con su nieto, un joven llamado Bolívar Celestino Celestino que tenía unos escasos 13 años y cursaba la secundaria. Nuestro primer encuentro fue revelador. En contraste con lo que había experimentado con los profesores, Bolívar no sabía leer su lengua, pero al escucharme leer las frases de los textos de Preuss pudo sin problema hablar de su contenido.

El contenido de los textos resultó ser de origen ritual y, por ende, muy distinto a la lengua cotidiana, a pesar de que las frases y las palabras no parecían tener mayor distancia de la lengua hablada. Trabajé con Bolívar los textos de Jesús María y, más tarde, los de San Francisco con Antonio Gutiérrez Rafael, un hombre de cerca de 50 años cuya familia también había mantenido una estrecha relación con la vida ceremonial de su pueblo.

En el transcurso de nueve meses logré concluir con cada uno de ellos una primera versión de la traducción de los cantos registrados por Preuss en Jesús María y San Francisco. Los resultados obtenidos eran reveladores y, sin embargo, subrayaban distintos problemas. Para empezar, ambos expertos recomendaban a continuación hacer reformas al texto original en cora para hacerlo "más claro". Estas modificaciones eran a veces simples, pero otras representaban verdaderas 


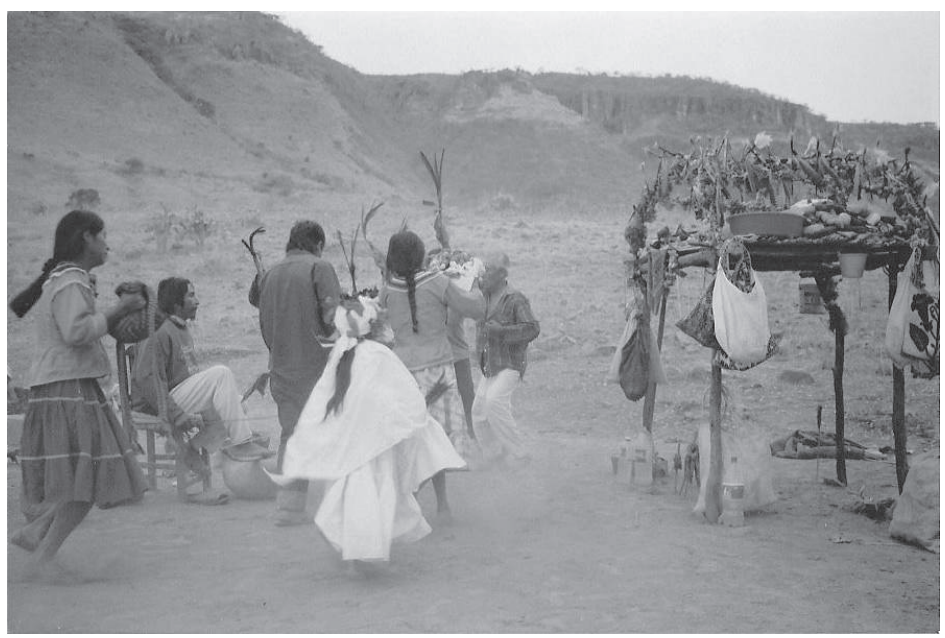

Fig. 7 - Mitote en el rancho de los Celestino

(foto M. Valdovinos Alba, 2005)

transformaciones. Este hecho me llevó a proponer un texto cora que servía de puente para la traducción que se había formulado con ambos traductores. En él se realizaban todas las modificaciones solicitadas por los traductores para mantener un equilibrio entre la traducción y el texto de base.

El texto original resultaba a veces sumamente difícil de traducir, lo que me hacía tener muchas dudas respecto a la validez de la versión en español obtenida. Al concluir el trabajo, Bolívar me dijo que, para él, el problema que teníamos residía en mi incapacidad para entender el ritual en el que se utilizaban los cantos. Había consultado con su abuelo y me proponía visitarlos en su rancho para observar lo que sucedía mientras se realizaba la enunciación de los cantos (Figura 7). Desde mi primera visita me percaté de la razón que tenía Bolívar y de la necesidad de profundizar en el estudio del ritual antes de publicar algo serio sobre los materiales de Preuss.

Decidí dedicar mi investigación doctoral al tema. Inicié realizando nuevos registros de los cantos. Con la nueva tecnología digital de la época logré grabar todos los cantos de los distintos rituales de mitote celebrados a lo largo del año. A partir de este material, transcribí y traduje al menos una de estas manifestaciones ceremoniales, que consistía en casi 12 horas de grabaciones (Valdovinos 2008). Este trabajo creó gran revuelo entre los especialistas náayeri, que nunca habían visto sus cantos escritos y mucho menos habían tenido ese material en papel como un elemento concreto y externo a ellos.

Durante distintas estancias en campo me reuní constantemente con los expertos rituales para hablar de su saber desde la nueva perspectiva que les ofrecía "ver" sus cantos y poder comentar su secuencia, su forma y su contenido desde una hoja 
de papel impresa. ${ }^{9}$ Nuestras pláticas comenzaban a abarcar nuevos temas relacionados con el texto cantado, como la forma de las danzas, la manera de participar en el ritual e incluso el método para aprender los cantos (ver Valdovinos 2008).

Mi relación con los aprendices y expertos rituales fue creciendo hasta el punto en que comenzaron a decirme que yo también quería aprender a cantar, ser un aprendiz de cantador como ellos. Yo siempre negué este rol, porque me parecía que iba mucho más allá de mis aspiraciones investigativas. Sin embargo, más tarde me di cuenta de que negar el proceso de aprendizaje es una de las principales características de todo aprendiz (ver Valdovinos 2008). Así que, en efecto, era yo una más entre ellos.

Al cabo de varios años de iniciada mi relación cercana con los especialistas, logré obtener la autorización para llevar al campo una copia digital de las grabaciones realizadas por Preuss para escucharlas con ellos. Era un acontecimiento que me resultaba muy emocionante. Sin embargo, el resultado de esta primera experiencia definió un rumbo insospechado para mi trabajo.

Organicé una primera sesión en la que varios cantadores expertos se reunieron para escuchar las grabaciones antiguas. Las hice sonar en mi computadora antes de salir de la pieza; los cantadores escucharon atentos la larga serie de grabaciones digitalizadas que se oían gracias a dos pequeñas bocinas. Al terminar, platicaron por un tiempo entre ellos y luego me llamaron para hablar conmigo. Su respuesta me sorprendió. Me dijeron con firmeza -y casi con lástima- que los cantos que les había llevado no eran de allí.

Su respuesta me dejó en shock. Era muy complicado para mí entender cómo ellos no podían reconocer el material que yo, con mi poco conocimiento, había logrado transcribir, clasificar y entender en parte. Pero esta incomprensión se convirtió en el punto de partida de un estrecho diálogo intercultural en el que, por mi parte, me comprometí a estudiar con detenimiento cómo Preuss había obtenido su material y ellos quedaron en trabajar conmigo para ayudarme a entender en qué aspectos se apoyaban para decir que los cantos no eran de allí.

Un punto importante para entender en qué consistían las grandes diferencias que los especialistas podían identificar a simple "escucha" solo salió a la luz gracias a que contábamos con las transcripciones contemporáneas de los cantos que se habían realizado en condiciones muy distintas a las grabaciones de Preuss. Con un mini disk que podía colocarse en la bolsa de la camisa del cantador atado a un micrófono de corbata, el equipo de grabación moderno era tan discreto que el cantador terminaba olvidando que lo llevaba puesto.

9. En este texto llamaré "expertos rituales" a las personas que se ocupan de dirigir y celebrar los rituales de mitote a los que hace referencia este trabajo. Se trata de expertos que deben prepararse para la tarea y que no dejan de formarse a lo largo de sus vidas en el conocimiento del ritual, sus reglas y sus posibles interpretaciones. 


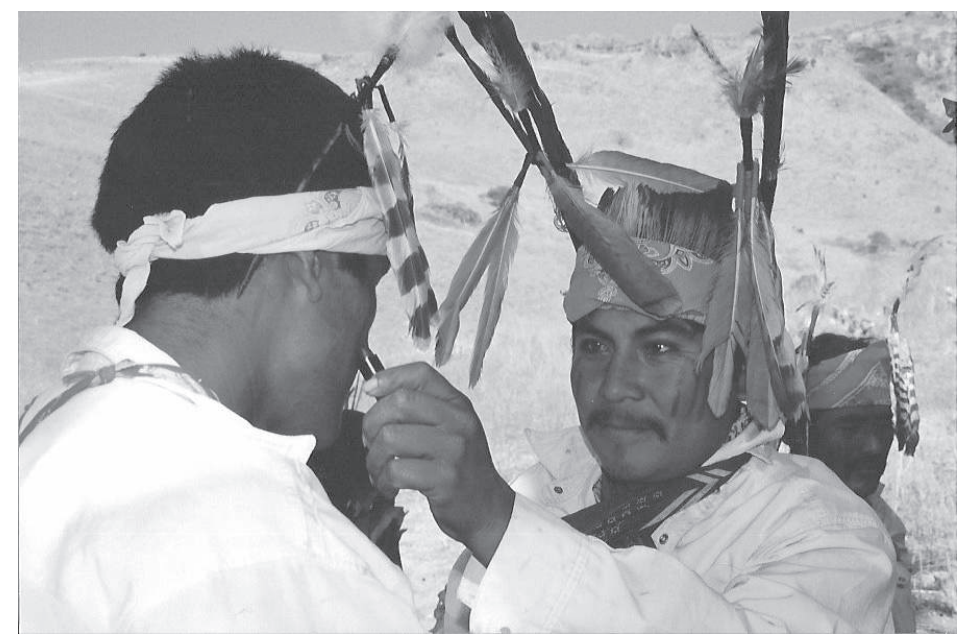

Fig. 8 - Las acciones rituales se desarrollan en paralelo al canto

(foto M. Valdovinos Alba, 2005)

La naturalidad que le daba al registro este discreto dispositivo permitió obtener grabaciones integrales de todos los cantos y de su secuencia a lo largo del ritual. Estas versiones completas permitieron corroborar que el material de Preuss consistía, en realidad, en pequeños fragmentos de los cantos completos, y permitieron identificar a qué canto se ligaba cada uno de los fragmentos obtenidos por Preuss. Además, puesto que las grabaciones contemporáneas se realizaron durante la performance ritual, se obtuvo un material que podía contrastarse con lo que sucedía durante su ejecución ceremonial (Figura 8).

La comparación entre el texto de los cantos de Preuss y la secuencia de los eventos rituales permitió observar que el material de Preuss presentaba rupturas en su secuencia con respecto a las versiones integrales grabadas in situ. Los "saltos" del material que los especialistas identificaron desde su primera escucha hacían pensar que los textos que habían sido narrados a Preuss no seguían la lógica del ritual o no le atribuían suficiente importancia a su secuencia y estructura. Estas observaciones llevaron a los especialistas rituales a pensar que quienes habían dictado los cantos a Preuss no eran forzosamente especialistas o que, simplemente, esos cantos pertenecían a otra tradición ajena a la suya, en la que no se respetaban las reglas elementales.

La relación entre el texto y el contexto que se mantenía en las nuevas grabaciones hizo posible señalar también otro elemento que, aunque ya había sido identificado, no había sido concebido como un elemento estructurante de la narrativa ceremonial náayeri. Me refiero aquí a las figuras discursivas formadas por estructuras paralelistas que se utilizan para ordenar el discurso ofreciendo un punto de partida para la organización del texto tanto espacial como temporalmente. 


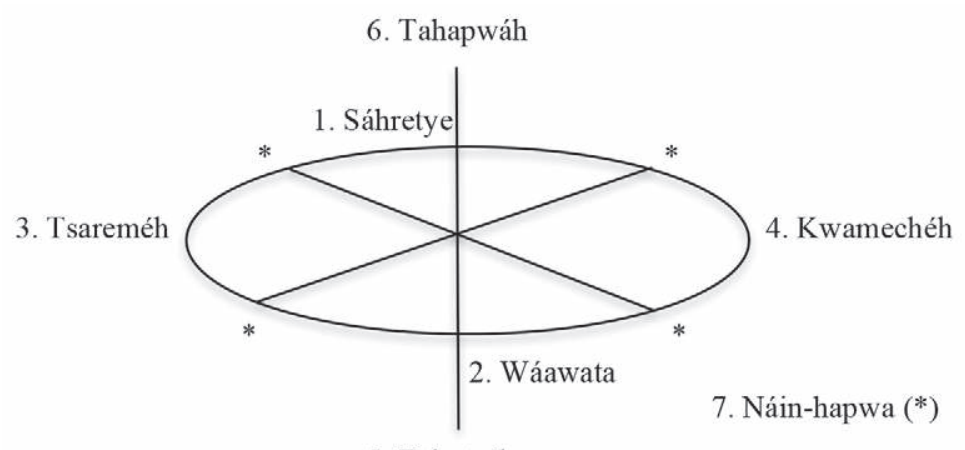

5. Tahetyéh

Fig. 9 - Secuencia de topónimos ceremoniales (M. Valdovinos Alba)

En los cantos rituales náayeri, las estructuras paralelistas corresponden a una secuencia de párrafos cuyo contenido parece idéntico con excepción de un término principal que varía en cada párrafo. Este término central que varía corresponde a un topónimo que hace referencia a un lugar preciso ubicado en una dirección particular del mundo. El conjunto de siete direcciones -1) oriente, 2) poniente, 3) norte, 4) sur, 5) abajo, 6) arriba y 7) "en todas partes"-, cuyo número y orden son siempre fijos, construye un mapa espacio-temporal que funciona como pauta en todas las expresiones gráficas, corporales y verbales que se relacionan con el mundo ceremonial náayeri (Figura 9). Su presencia permite rememorar el orden del tiempo y el espacio y embellecer de una manera particular las manifestaciones que lo incluyen, ya sean cantos, danzas, oraciones, ofrendas, objetos, etcétera. Debido a sus funciones mnemónica y estética, me he referido antes a este modelo como "estructura mnemopoética" (Valdovinos 2019).

En los textos grabados por Preuss, las estructuras paralelistas aparecen por lo general truncadas, es decir, no siguen el orden establecido o brincan de un topónimo a otro sin respetar la secuencia fija. Este punto resultó ser muy desconcertante para los especialistas rituales contemporáneos, quienes conciben como una de las reglas más esenciales de su labor ceremonial respetar la secuencia y el orden de los elementos de estas estructuras mnemopoéticas.

$\mathrm{Al}$ comparar los textos integrales y su relación con la acción ritual con las versiones fragmentarias e imperfectas de Preuss, se pudo también identificar una deformación en el uso de partículas locativas y marcadores epistémicos. La ausencia y el uso poco común de estas partículas, que generalmente son muy numerosas en el género ritual náayeri, contrasta fuertemente en los materiales registrados por Preuss. La única explicación de su ausencia tiene que ver con la situación de la enunciación en la que se registraron los cantos: fuera de la acción ritual, en un contexto en el que el cantador no podía describir cómo 
observaba la acción delante de él; sobra decir que el desarrollo de los cantos va de la mano del desarrollo de las acciones danzadas que se realizan de manera simultánea a la enunciación.

En el caso del registro contemporáneo, los cantos se grabaron siempre en el ritual. Por esta razón, tanto los prefijos locativos como los marcadores evidenciales que evocan la situación de la acción con respecto al cantador se manifiestan siguiendo un patrón fijo y formal que difiere de la irregularidad con la que aparecen en los textos registrados por Preuss. Es evidente que este aspecto fue otra de las fuentes de confusión para los especialistas contemporáneos al momento de interpretar el estatus de los cantos registrados por el etnólogo alemán.

Vale la pena mencionar un último aspecto que surgió como resultado de la fase final del análisis. Al comparar los textos transcritos por Preuss y el contenido de sus grabaciones se observó que ambas formas de registro presentaban diferencias importantes con respecto a los textos contemporáneos. Por la naturaleza de estas diferencias, no parece tratarse de modificaciones que resultan del paso del tiempo, sino más bien de cambios que tienen que ver con la forma del registro.

Las grabaciones de fonógrafo presentaban saltos en el argumento que seguramente resultaron del particular dispositivo de grabación del aparato: cada cilindro de cera no podía contener más que aproximadamente tres minutos de grabación. Los cantadores que grabaron sus voces en estos soportes "resumieron" sus cantos para dejar en cada cilindro al menos una estructura paralelista completa, aunque esto supusiera brincarse algunos componentes del texto cantado.

Si bien el contenido de las grabaciones históricas presenta este tipo de variaciones, la forma de los cantos que contienen es testigo de la continuidad de su estructura poética. En efecto, la estructura prosódica presente en los cantos grabados por Preuss se encuentra registrada tal como se observaba en sus versiones contemporáneas, es decir, con abundantes repeticiones que contienen numerosas marcas epistémicas y locativas. Estos marcadores semánticos aparecen como delimitadores de frases cortas que, como en los cantos contemporáneos en su versión integral, atribuyen una cadencia particular al texto, imprimiéndole una melodía característica.

Una situación muy diferente se identificó en los textos registrados por Preuss a partir de los dictados. En ellos, la estructura repetitiva y cadenciosa del texto característica de los cantos rituales está ausente. Esta forma es sustituida por expresiones narrativas más próximas a un discurso narrativo que cumple la función de explicar o narrar el contenido de los textos rituales náayeri. En este sentido, los dictados exponen un texto cuyo contenido expone la secuencia ritual y sus detalles, pero se aleja de la estructura prosódica formada por frases cortas característica de los cantos ceremoniales náayeri.

Estas observaciones me han llevado a plantear que el material de Preuss corresponde a un discurso híbrido (Valdvinos 2019a) que toma como punto de partida el discurso ritual náayeri, pero difiere de él tanto en su forma-sobre 
todo en el caso de los dictados- como en su contenido -sobre todo en el caso de las grabaciones-. Este contraste se crea no tanto por el conocimiento de los especialistas que trabajaron con Preuss, sino por la necesidad que tuvieron de responder a las expectativas del registro. Así, aunque se trata de un modo discursivo que intentaba retomar los elementos del discurso ritual, se convirtió en un discurso que explicaba o exponía el contenido del discurso ritual, sin reproducir sus características más esenciales.

\section{Particularidades de la repatriación}

Hasta aquí he expuesto de qué manera el estudio que realicé sobre los materiales literarios náayeri fue articulando aquellos materiales que corresponden al trabajo de Preuss y aquellos que se documentaron más recientemente. He planteado que fue justamente este encuentro lo que ofreció luz para entender la dinámica de la tradición ceremonial náayeri. En todo este proceso analítico participaron activamente distintos especialistas rituales, quienes no solo ocuparon el puesto de revisores o traductores, sino que actuaron como verdaderos interlocutores con los que busqué resolver los diferentes retos que fueron surgiendo para la comprensión del material literario náayeri.

Siguiendo las disposiciones de los especialistas rituales, se estableció un plan editorial que iniciaba con la publicación del CD con las grabaciones antiguas (Preuss 2013). Luego se retomaría la publicación del material transcrito por Preuss (Preuss 2020) y posteriormente se publicarían los textos contemporáneos (Valdovinos 2008), para lo cual los especialistas juzgaron necesario observar primero la reacción del público ante este tipo de materiales nunca antes publicados con la publicación de un único canto (Valdovinos 2019) ${ }^{10}$.

Este proceso en su conjunto representa para mí la repatriación de los cantos náayeri. En este sentido, la repatriación consiste en un proceso complejo, y no simplemente en un movimiento único de retorno de un bien patrimonial del lugar de donde se resguardó hasta el lugar donde se registró originalmente. Así, la repatriación de los cantos de mitote dio inicio en 1998, con la llegada del material publicado por Preuss a la comunidad y con su respectiva presentación ante los especialistas rituales para obtener una traducción al español. El diálogo generado por esta primera etapa de encuentro intercultural fue seguido por una segunda etapa, esta vez relacionada con la llegada de las versiones digitales de las grabaciones de Preuss. La preparación del CD para publicar una selección de cantos coras y huicholes fue en realidad una condición necesaria para lograr que se autorizara la salida del material del Archivo Fonográfico. Al mismo tiempo, su edición garantizaba el regreso abierto y definitivo de este material a la comunidad.

10. Cabe recordar aquí que el libro de Preuss publicado en 1912 tuvo muy poca distribución en México y prácticamente nula presencia en la Sierra Madre Occidental. 
El proceso de repatriación al que aquí me refiero supuso una negociación intercultural constante ante los especialistas rituales. Luego de haber escuchado las grabaciones de Preuss, los especialistas determinaron que el material era tan problemático que era muy posible que no se tratara de textos de Jesús María. Para enfrentar esta disyuntiva, se procedió a realizar una investigación en dos direcciones. Por un lado, se buscó reconstruir el método de Preuss y los detalles de su expedición; por otro lado, se estudiaron las transcripciones de sus grabaciones con detenimiento para traducir los textos y analizar los aspectos que los especialistas señalaban como problemáticos. Ambas investigaciones sirvieron para preparar el estudio que acompaña el CD (Preuss 2013).

Gracias al proceso de estudio del material, los especialistas rituales consultados reforzaron su posición de conocedores ante mí, pero también ante otras esferas de la comunidad. En primer lugar, mostraron que su saber era más adecuado para tratar ciertas manifestaciones de su lengua que la de los maestros bilingües, que en la dinámica local son concebidos por ellos como quienes buscan apropiarse del saber tradicional para entregarlo a la Secretaría de Educación Pública y obtener provecho de esta transacción. En segundo lugar, con la publicación del CD de los cantos antiguos, los especialistas rituales lograron presentarse abiertamente a través de las instancias oficiales ante la comunidad como expertos reconocidos desde el exterior gracias a su conocimiento sobre el tema ceremonial.

El trabajo de reconstrucción histórica demostró que los especialistas tenían razón en señalar problemas estructurales en los textos grabados por Preuss. Si bien se trataba de textos de Jesús María, la forma de registro había impactado de tal manera la naturaleza del material, que era problemático considerarlo como una evidencia de la tradición náayeri de tiempos más antiguos.

Al tomar en serio las observaciones de los especialistas se pudieron estudiar con detenimiento sus indicaciones. Se determinó que las fallas del texto correspondían a problemas concretos sobre la forma y el contenido de los cantos relacionados con la manera en la que habían sido registrados. Los especialistas optaron por no detener la edición, pero sí plantearon la importancia de que, para su difusión, las grabaciones estuvieran acompañadas de un estudio explicativo que diera cuenta de los problemas identificados por ellos. Su posición en tanto expertos incuestionables del saber ritual de su comunidad se consolidó aún más con la realización de entrevistas y encuentros que se realizaron en el marco de la entrega de los CD a la comunidad por parte de las instituciones que financiaron el proyecto (Figuras 10 y 11, página siguiente). La entrega se difundió además a través de la radio local: XEJMN. La voz de los cuatro pueblos.

La estación de radio local ha tenido un papel importante en el proceso de repatriación de los materiales de Preuss. Al igual que los maestros, desde que inicié el estudio de los cantos rituales, los trabajadores de la radio me solicitaron en repetidas ocasiones disponer del material que estudiaba y que registraba. 
Margarita Valdovinos Alba

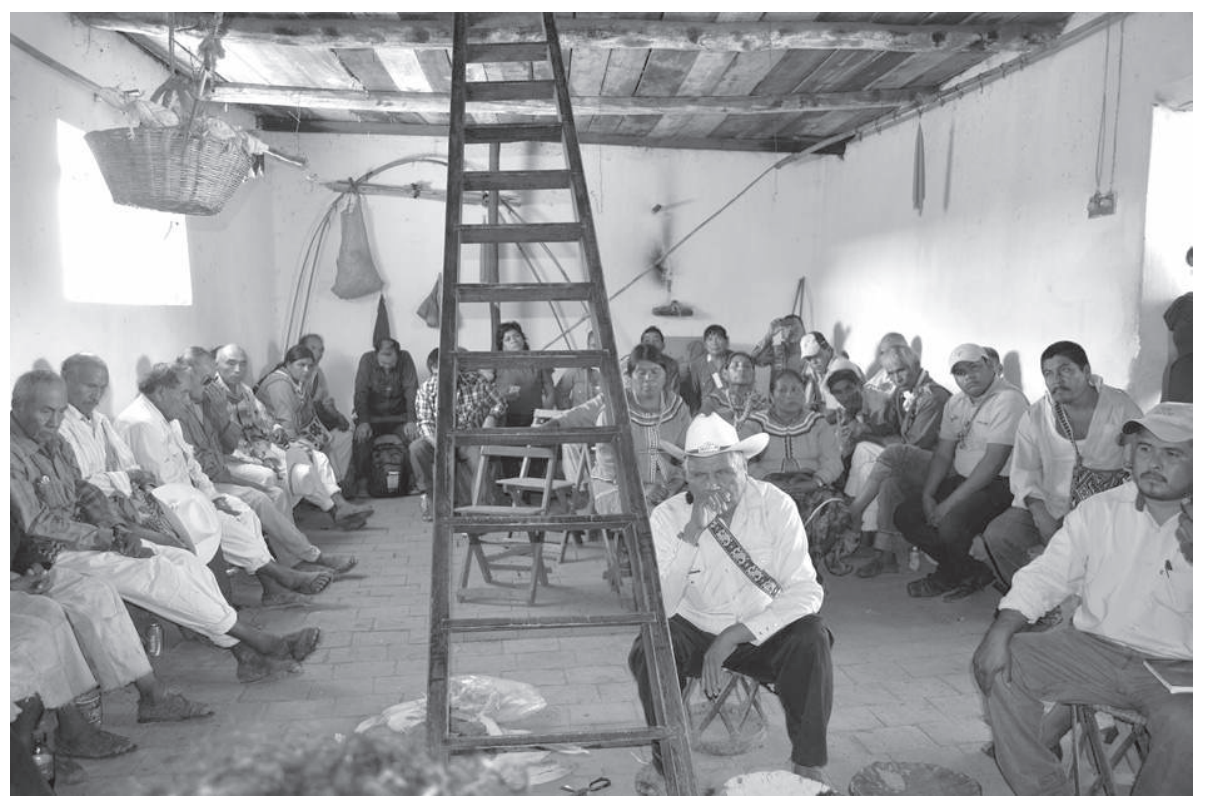

Fig. 10 - Ceremonia de entrega del CD ante las autoridades tradicionales de Jesús María (foto Arnulfo Embriz, 2014)

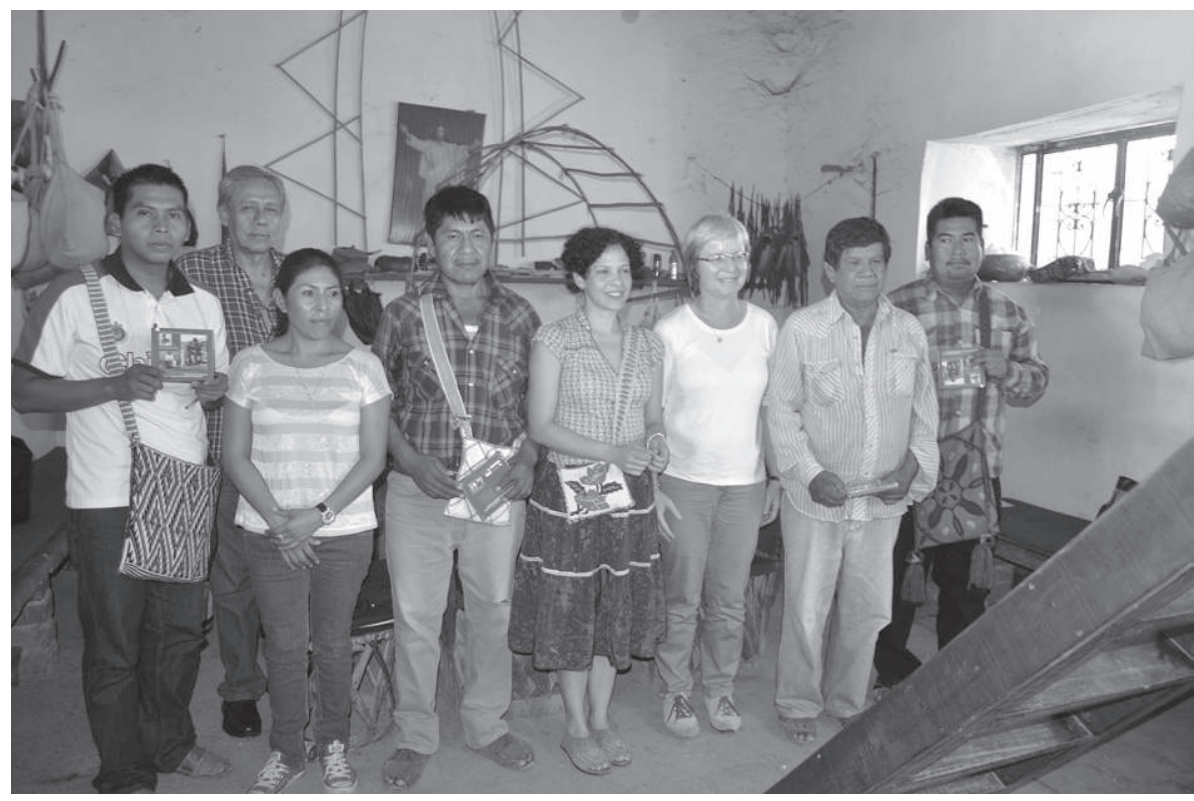

Fig. 11 - Ceremonia de entrega del CD ante las autoridades tradicionales de Jesús María (foto Arnulfo Embriz, 2014) 
Siempre negué el acceso debido al compromiso que había adquirido con los especialistas a quienes había grabado, quienes desde el inicio me solicitaron no compartir el material con nadie hasta que el estudio estuviera concluido. Esta prohibición hacía particular referencia a los maestros y a los medios locales de comunicación, pues en ambos casos se consideraba que los responsables nunca habían mostrado pruebas de acercarse a los eventos tradicionales para tratar de entender su lógica interna y considerar sus materiales con el debido respeto.

Los especialistas juzgaban que la radio no sabría interpretar el material y lo presentaría de manera descontextualizada en sus emisiones de radio, como había sucedido con otras grabaciones de cantos rituales que se habían obtenido de otros proyectos de registro. La radio obtuvo las grabaciones antiguas solamente una vez que se publicó el CD. Durante la entrega del material publicado a la radio se realizaron diferentes actividades para presentarlo y familiarizar a los locutores con su naturaleza. En particular, se organizó un encuentro entre locutores y especialistas, en donde se entrevistó a especialistas rituales para que ellos hablaran tanto de las grabaciones de Preuss como del ritual de donde provenían (Figura 12).

Este nuevo espacio de diálogo nunca antes visto logró aproximar a dos sectores de la sociedad que se caracterizan por ser especialistas de la palabra en dos ámbitos muy separados de la vida social: los especialistas rituales que

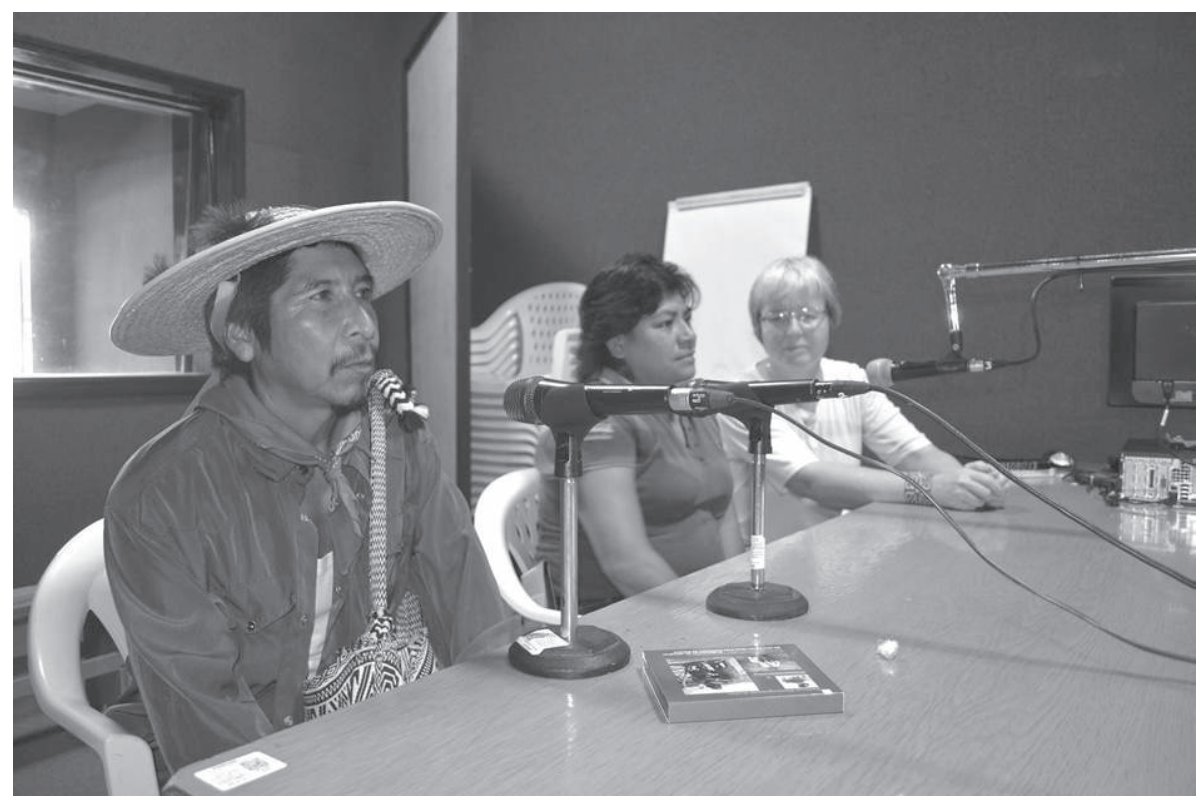

Fig. 12 - Entrevista de los especialistas en la radio local

(foto M. Valdovinos Alba, 2014) 
dominan el costumbre (las prácticas con las que se materializan las creencias náayeri) y los locutores de radio que dominan las relaciones interculturales en el contexto serrano.

Además de este encuentro de oradores especializados, el material repatriado tuvo distintos efectos en la sociedad cora. Entre los no especialistas, el interés del exterior sobre una tradición considerada como algo del pasado, volvió a atraer miradas hacia el mitote. Ante los especialistas, este material ofreció un nuevo contexto para hablar de sus cantos y de los procesos que llevan a su continuidad, su transformación, su olvido y su sobrevivencia. En este sentido, la repatriación de los cantos de Preuss transformó la manera en la que ellos mismos concebían su aprendizaje de los cantos y la manera en la que creen que este saber puede seguir ocupando un lugar en la cultura local.

Entre los especialistas, la repatriación produjo también distintas reacciones en distintos momentos. Primero se les vio con rechazo, luego con curiosidad y, más tarde, como un objeto que les permitía posicionarse como figuras de autoridad para definir la manera en la que el material debía ser presentado ante el resto de la comunidad. En ningún momento se idealizó el material, al contrario, se discutió la pertinencia de difundir un material "tan defectuoso" desde los ojos de los especialistas.

Hace falta esperar unos años más para ver qué tipo de transformaciones se despiertan de todo este proceso, pero por el momento se puede decir que la presencia de los cantos registrados por Preuss, aunados a los estudios contemporáneos del material, despertaron una nueva curiosidad en los especialistas por entender los mecanismos de su tradición.

\section{Conclusión}

La repatriación digital de los cantos náayeri grabados por Preuss aportó nuevos elementos para que los especialistas rituales reflexionaran abiertamente sobre su tradición y la transformación que ha sufrido a través del tiempo. En este proceso, su participación ha supuesto una posición crítica que se aleja radicalmente de la idealización del objeto repatriado. Así, nunca ha sido cuestión para ellos ensalzar los registros antiguos de los cantos rituales o adoptar alguna actitud que conduzca a ver este material como un nuevo objeto de culto. Al contrario, al solicitar que el CD conteniendo los cantos de Preuss fuera acompañado de una explicación que diera cuenta explícita de los problemas de forma y contenido del material, los especialistas expusieron ostensivamente la falta de reverencia que despiertan estos materiales ante ellos. No estoy convencida de que esta lógica funcione para todos. Me imagino sin dificultad que, mientras que los especialistas mantendrán una visión crítica sobre los materiales de Preuss, otros sectores de la sociedad náayeri, de la población de la región o incluso el Estado podrán retomar este material para convertirlo en un objeto de glorificación de la historia 
del pueblo náayeri y de sus tradiciones. En este proceso de reinterpretación de las evidencias del pasado, me parece importante -aunque no sorprendente- apuntar simplemente que son los sectores mejor informados sobre el tema los que mantienen una posición crítica, mientras que los sectores menos informados terminan por construir nuevos mitos del conocimiento sobre evidencias antiguas del saber ceremonial (Figura 13).

En todo caso, la repatriación de los cantos náayeri registrados por Preuss ofrece un ejemplo del proceso de repatriación como catalizador que, si bien por un lado vuelve a subrayar la importancia de un grupo de conocedores ante su comunidad (los expertos rituales) y ofrece a este sector nuevos elementos para evaluar sus prácticas de aprendizaje y transmisión, otorga también a otros grupos más marginales la posibilidad de construirse un discurso respecto de esos saberes y participar en la evaluación colectiva que permite definir qué es la tradición.

La repatriación de los cantos anti-

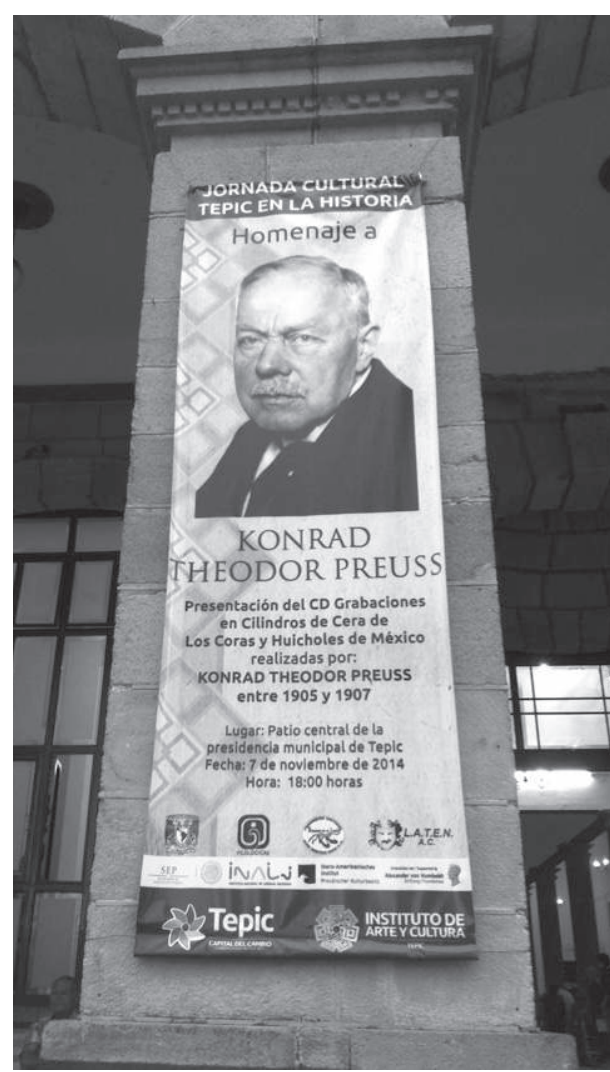

Fig. 13 - Poster sobre la presentación del CD en Tepic (foto M. Valdovinos Alba, 2014) guos náayeri aún no ha terminado.

Pronto llegarán nuevos impresos sobre los dictados de Preuss a las comunidades náayeri. Aquí, el sector escolar tendrá nuevas maneras de reivindicarse ante este material y nuevos espacios para entrar en contacto con los expertos rituales que conforman los sectores más tradicionales de la vida ceremonial de sus comunidades. Estos nuevos procesos estarán aún por verse y necesitarán seguir siendo observados y analizados. Tal vez entonces un nuevo diálogo se instaurará, ya no solo entre especialistas de la palabra, sino entre especialistas del saber. Para los investigadores nos queda preguntarnos qué tan confiables son los archivos del pasado en ausencia de un análisis crítico y profundo. Para los coras, tal vez nuevos encuentros epistemológicos logren desencadenar nuevos puentes para la comunicación entre distintas visiones del saber que existen también en el seno de sus comunidades. *

* Manuscrit reçu en janvier 2020, accepté pour publication en octobre 2020. 
Agradezco el apoyo del Instituto Ibero-Americano de Berlín y a la Fundación Alexander von Humboldt por el apoyo que me brindaron para la preparación de una primera versión de este texto.

\section{Referencias citadas}

Buschmann Johann Carl Eduard

1859 Die Spuren der aztekischen Sprache im nördlichen Mexico und höheren amerikanischen Norden. Zugleich eine Musterung der Völker und Sprachen des nördlichen Mexiko's und der Westseite Nordamerika's von Guadalajara an bis zum Eismeer, I. Hauptband, Gedruckt in der Buchdruckerei der Königlichen Akademie der Wissenschaften, Berlín.

Canio Llanquinao Margarita y Gabriel Pozo Menares

2013 Historia y conocimiento oral mapuche. Sobrevivientes de la "Campaña del Desierto" y "Ocupación de la Araucanía” (1899-1926), Consejo Nacional de la Cultura y las Artes, Santiago.

Humboldt Alexander von

1810 Vue des Cordillères, et monuments des peuples indigènes de l'Amérique. Voyage de Humboldt et Bonpland. Première partie. Relation Historique. Atlas Pittoresque, chez F. Schoell, Paris.

Instituto Nacional de Lenguas Indígenas (Inali)

2008 "Catálogo de las lenguas indígenas nacionales: variantes lingüísticas de Mexico con sus autodeterminaciones y referencias geoestadísticas", Diario Oficial de la Federación, el 14 de enero de 2008, México.

JÁuREGUI Jesús

2004 Coras, Comisión Nacional para el Desarrollo de los Pueblos Indígenas/ Programa de las Naciones Unidas para el Desarrollo, México.

LeHMANN-Nitsche Robert

2009 Robert Lehmann-Nitsche. Walzenaufnahmen aus Argentinien (1905-1909), Lars Christian Koch y Suzanne Ziegler (eds), Ethnologisches Museum zu Berlin (Berliner Phonogramm-Archiv. Historische Klangdokumente, 4/5)/ Ibero-Amerikanisches Institut, Berlin.

Lumholtz Carl S.

1900 Symbolism of the Huichol Indians (Memoirs III), American Museum of Natural History, New York.

1902 Unknown Mexico. A Record of Five Year's Exploration Among the Tribes of the Western Sierra Madre; in the Tierra Caliente of Tepic and Jalisco; and Among the Tarascos of Michoacan, Charles Scribner's Sons, New York.

Malvestitti Marisa

2012 Mongeleluchi Zungu. Los textos araucanos documentados por Roberto Lehmann-Nitsche, Ibero-Amerikanisches Institut, Berlin.

Neurath Johannes y Jesús JÁuREGUI

1998 "La expedición de Konrad Theodor Preuss al Nayarit (1905-1907) y su contribución a la mexicanística", in Jesús Jáuregui y Johannes Neurath (comps.), Fiesta, literatura y magia en el Nayarit. Ensayos sobre coras, huicholes y 
El caso de las grabaciones rituales náayeri registradas por K. Th. Preuss

mexicaneros de Konrad Theodor Preuss, Instituto Nacional Indigenista/Centre d'études mexicains et centroaméricains, México, p. 15-60.

Preuss Konrad Theodor

1912 Die Nayarit-Expedition. Textaufnahmen und Beobachtungen unter mexikanischen Indianern, Erster Band, Die Religion der Cora-Indianer, Teubner, Leipzig.

1932 "Grammatik der Cora-sprache", International Journal of American Linguistics, $7(1 / 2)$, p. 1-84.

2013 Walzenaufnahmen der Cora und Huichol aus Mexiko 1905-1907, grabación de sonido, Staatliche Museen zu Berlin (Historische Klangdokumente, 9)/ Ibero-Amerikanisches Institut, Berlin/Instituto Nacional de Lenguas Indígenas, México, CD.

2020 La exploración al Nayarit. Registro de textos y observaciones entre los indígenas mexicanos, edición en español crítica y comentada por Margarita Valdovinos, Siglo XXI Editores/Universidad Nacional Autónoma de México/ Instituto Nacional de Antropología e Historia/Instituto Ibero-Americano de Berlín, Ciudad de México.

VALDOvinos Margarita

2002 Los cargos del pueblo de Jesús María (Chuísete'e). Una réplica de la cosmovisión cora, tesis de licenciatura en etnología, Escuela Nacional de Antropología e Historia, México.

2008 Les chants de mitote cora. Une pratique discursive au sein de l'action rituelle, tesis de doctorado en etnología, université Paris Ouest Nanterre La Défense, Nanterre.

2012 "La materialidad de la palabra. La labor etnolingüística de Konrad Theodor Preuss en torno a su expedición a México", Baessler-Archiv, 60, p. 67-86.

2013a "Stimmen und Gesänge der Sierra Madre. Die Tonaufnahmen der Cora und Huichol von Konrad Theodor Preuss", in Margarita Valdovinos (coord.), Walzenaufnahmen der Cora und Huichol aus Mexiko 1905-1907, Lars Christian Koch y Suzanne Ziegler (eds.), Staatliche Museen zu Berlin (Historische Klangdokumente, 9)/Ibero-Amerikanisches Institut, Berlin/Instituto Nacional de Lenguas Indígenas, México, p. 77-82.

2013b "Die Tonaufnahmen der Cora", in Margarita Valdovinos (coord.), Walzenaufnahmen der Cora und Huichol aus Mexiko 1905-1907, Lars Christian Koch y Suzanne Ziegler (eds.), Staatliche Museen zu Berlin (Historische Klangdokumente, 9)/Ibero-Amerikanisches Institut, Berlin/Instituto Nacional de Lenguas Indígenas, México, p. 89-93.

2013c "Las dinámicas de clasificación y exposición de las colecciones etnográficas en el Museo Etnológico de Berlín a través de algunos ejemplos americanos", Journal de la Société des américanistes, 99 (2), p. 165-196.

2017 "Cilindros de cera en la Sierra Madre Occidental: el diálogo en la retribución de los archivos sonoros de K. Th. Preuss a los Náayeri del Occidente de México", Música em contexto. Revista do Programa de Pós-Graduacao Música en Contexto da Universidade de Brasília, 11 (1), p. 223-239.

2019 El canto de la chicharra y el encantamiento del mundo, Universidad Nacional Autónoma de México, México. 
VALDOVINOS Margarita

2020a "El trabajo etnolingüístico de Konrad Theodor Preuss en México y Colombia a inicios del siglo XX. Creación y desarrollo de un método de estudio para las literaturas y las lenguas amerindias", Anthropos, 115 (2), p. 503-526.

2020 b "Comentarios sobre la transcripción y la traducción", La exploración al Nayarit. Registro de textos y observaciones entre los indígenas mexicanos, edición en español crítica y comentada por Margarita Valdovinos, Siglo XXI Editores/Universidad Nacional Autónoma de México/Instituto Nacional de Antropología e Historia/Instituto Ibero-Americano de Berlín, Ciudad de México, vol. 1, p. CI-CXIII.

2020c "Proceso editorial: de la Libreta VII a la edición original", La exploración al Nayarit. Registro de textos y observaciones entre los indigenas mexicanos, edición en español crítica y comentada por Margarita Valdovinos, Siglo XXI Editores/Universidad Nacional Autónoma de México/Instituto Nacional de Antropología e Historia/Instituto Ibero-Americano de Berlín, Ciudad de México, vol. 3, p. CXXXI-CCXVIII).

VALDOvinos Margarita y Susanne ZiegleR

2013 "Die Sammlung 'Preuss Mexiko"”, in Margarita Valdovinos (coord.), Konrad Theodor Preuss Walzenaufnahmen der Cora und Huichol aus Mexiko 19051907, Lars Christian Koch y Suzanne Ziegler (eds.), Staatliche Museen zu Berlin (Historische Klangdokumente, 9)/Ibero-Amerikanisches Institut, Berlin/ Instituto Nacional de Lenguas Indígenas, México, p. 73-75.

WiedMann Albrecht

2006 "Conservation and digitalisation of the holdings of the Phonogramm-Archiv", in Susanne Ziegler (ed.), Die Wachszylinder des Berliner PhonogrammArchivs, Ethnologisches Museum zum Berlin/Staatliche Museen zu Berlin, Berlin, p. 56-58.

ZIEGLER Susanne

2006 Die Wachszylinder des Berliner Phonogramm-Archivs, Ethnologisches Museum/Staatliche Museen zu Berlin, Berlin.

ZIEHM Elsa

1968 Nahua-Texte aus San Pedro Jicora in Durango. Erster Teil: Mythen und Sagen, Gebr. Mann Verlag (Quellenwerke Zur Alten Geschische Amerikas Aufgezeichnet in Den Sprachen der Eingeborenen, 9), Berlin.

1971 Nahua-Texte aus San Pedro Jicora in Durango. Zweiter Teil: Märchen und Schwänke, Aufgezeichnet von Konrad Theodor Preuss aus dem Nachlass übersetzt und herausgegeben von Elsa Ziehm, Gebr. Mann Verlag (Quellenwerke Zur Alten Geschische Amerikas Aufgezeichnet in Den Sprachen der Eingeborenen, 10), Berlin.

1976 Nahua-Texte aus San Pedro Jicora in Durango. Dritter Teil: Gebete und Gesänge, Aufgezeichnet von Konrad Theodor Preuss aus dem Nachlass übersetzt und herausgegeben von Elsa Ziehm mit einem Kapitel über die Musik der drei von Preuss besuchten Stämme, Gebr. Mann Verlag (Quellenwerke Zur Alten Geschische Amerikas Aufgezeichnet in Den Sprachen der Eingeborenen, 11), Berlin. 